\title{
La cultura organizativa en agrupaciones juveniles de Medellín y Barranquilla*
}

\author{
César Augusto Gaviria
}

Recibido: 20 de febrero de 2012 Aprobado: 27 de marzo de 2012

\begin{abstract}
Resumen
El presente artículo es el resultado de la investigación acerca de la cultura organizativa de ocho organizaciones juveniles de Medellín y Barranquilla. Aquí el término cultura organizativa -no cultura organizacional-adquiere un significado especial, pues señala la orientación pretendida: basada en teoría sociológica, esta indagación pretendió un enriquecimiento de la teoría tradicional con la que se han analizado las organizaciones en general. En esta tarea, la entrevista individual y grupal a los integrantes de cada grupo fue clave para la construcción de la memoria grupal, desde donde se construyen las descripciones acerca de las coincidencias y diferencias del objeto de estudio. Al final, se establecen cuatro fases de las historias de las agrupaciones, algunas características organizativas, y se exponen algunos aspectos propios de situaciones comunes a las organizaciones estudiadas, específicamente en relación con la toma de decisiones, las actividades, la gestión, y el diálogo ante el Estado y otras organizaciones.
\end{abstract}

Palabras clave: organizaciones juveniles, cultura organizativa, memoria.

* El presente artículo es producto de la investigación titulada "Organizaciones Juveniles: ¿Espacios de legitimación, resistencia o alternatividad? - Estudio comparativo de Medellín y Barranquilla" desarrollada entre los años 2009 -2010 conjuntamente por la Colegiatura Colombiana de Medellín, la Universidad de Antioquia y Universidad del Norte. Esta investigación fue adelantada por los profesores Jair Vega, Mónica Pérez y quien escribe este escrito. Cada uno abordó aspectos distintos del objeto de estudio. Específicamente, correspondió al presente autor estudiar los aspectos que intervienen en la cultura organizativa de cada una de las organizaciones juveniles en cuestión.

** Magister en Historia de la Universidad Nacional y Especialista en Ciencia Política de la Universidad Nacional, Medellín- Colombia. Comunicador Social Periodista de la Universidad de Antioquia, Medellín-Colombia.Correo electrónico: maestrogaviria@gmail.com. 


\title{
Organizing Culture in Juvenile Groups from Medellin and Barranquilla
}

\begin{abstract}
This article is the result of a research about the organizing culture of eight juvenile organizations from Medellin and Barranquilla. In this article, the term "organizing culture" (not "organizational culture") involves a special meaning since it points out the expected orientation: Based on the sociological theory, this research was intended to enrich the traditional theory used for analyzing organizations in general. Individual and group interview to the members of each group was a key factor for constructing the group memory over which descriptions about coincidences and differences of the study object were built. Finally, the article introduces four stages of groups' histories and some organizing characteristic, and some aspects inherent to common situations of the organizations studied are exhibited, specifically in relation to decision making, activities, management, and dialogue with the State and other organizations.
\end{abstract}

Key words: Juvenile organizations; organizing culture; memory. 


\section{Introducción}

En Medellín y Barranquilla existen una serie de asociaciones y corporaciones juveniles que en su mayoría son apéndices de organizaciones adultas de corte religioso o partidista. Sin embargo, hay otras organizaciones surgidas por fuera de la intervención adulta y/o estatal. Un grupo de estas últimas fue objeto de estudio para este escrito acerca de la cultura organizativa en 8 organizaciones juveniles de ambas ciudades. Las organizaciones analizadas en Medellín fueron: Pasolini en Medellín, Siglo XXI, Amigos Unidos y Puerta Abierta. Y en Barranquilla fueron: Pimentón Rojo, Puerta de Hierro, Cazadores de Auroras y Buenos Muchachos. La escogencia se hizo con base en el desarrollo que ellas en los últimos años hayan tenido de algún proyecto social relacionado con la comunicación mediática (uso de medios de comunicación tradicionales), la transferencia de medios (apropiación o capacitación en cine, fotografía o video), o la comunicación cultural alternativa (teatro, música, danza).

En este proceso investigativo se analizó la memoria grupal como elemento clave para determinar la cultura organizativa relativa a los fines explícitos de las actividades realizadas, así como valores y creencias que dan forma a la cultura presente en cada una de ellas. Desde allí, el análisis de la estructura intuitiva de procedimientos que ha posibilitado la realización de actividades y procesos internos de estos grupos (cuyos fines son sociales o culturales, no necesariamente lucrativos), tomó elementos teóricos de la sociología. Así, la pregunta central de esta indagación apuntó a las características de la cultura organizativa de las agrupaciones estudiadas a partir de lo que hoy son y lo que han sido en momentos clave de su historial organizativo. Si la organización es coordinación del trabajo, si la organización es colaboración para la realización de tareas, surgían preguntas complementarias tales como: estas agrupaciones juveniles, ¿cómo se organizan?, ¿̇de qué manera sus objetivos influyen en sus acciones?, chasta qué punto sus acciones están condicionadas por las presiones externas de todo tipo?

Lo anterior significaba el establecimiento de las particularidades propias de un objeto de estudio maleable al que muchos autores han reducido a cifras y estructuras formales de articulación. No obstante, se quiso trascender la perspectiva empresarial en la que preponderantemente se ha encuadrado la investigación en comunicación de las organizaciones, más cercana a la perspectiva administrativista -empresarial-. De allí que para esta indagación el análisis de la organización se concentra en quienes la componen y ejecutan (los humanos), y no reducida a uno de sus fines. En otras palabras, 'organización' puede ser tanto el grupo humano organizado cuyos objetivos son lucrativos, como también aquel que persigue unos fines sociales, políticos o culturales.

\section{Bases teóricas}

En un intento por superar la utilización que en las últimas décadas se ha hecho de la comunicación como una simple expresión "comodín" (Thayer, 1975, p. 29), partimos del presupuesto de que la comunicación posibilita la organización y en la organización se genera la cultura organizativa. Es bien sabido que existe un mutualismo, explícito o implícito, entre los procesos organizativos y los procesos comunicativos de cada grupo humano. Por ello se puede considerar que la cultura organizativa es comunicación. "Podríamos decir muy pocas cosas sobre la comunicación o la conducta humana sin tener en consideración la forma como las personas contribuyen a $-\mathrm{y}$ depende de- los esquemas mediante los cuales son organizadas o se organizan a sí mismas, para fines concretos" (Thayer, 1975, p. 29).

Igualmente, decimos que de la cultura se desprenden las manifestaciones comunicativas, y las formas comunicativas construyen la cultura. Ambas se nutren mutuamente. Por ejemplo, 
sería difícil hablar del comportamiento humano sin analizar el proceso de comunicación, y a su vez sería complicado pensar la comunicación sin contar con la complejidad de la cultura humana. "La comunicación es tanto el modo de recibir la cultura como el instrumento utilizado en su construcción" (Lucas Marín, 1997, p. 76). Es decir, estos tres términos, 'comunicación', 'organización' y 'cultura', se convierten en una red entrelazada de elementos significativos ubicados en el trasfondo del análisis de las sociedades contemporáneas.

Para Jesús Martín-Barbero, la investigación social no puede eludir los retos que plantean los fenómenos de la comunicación de hoy. Para ello hay que superar los tres principales reduccionismos de las teorías tradicionales de la comunicación: "el que creía poder explicar el funcionamiento de los medios de comunicación como un proceso de mero acoplamiento ideológico, el que creía poder explicar la organización de las instituciones comunicativas por la sola lógica del mercado, y finalmente el que creía poder explicar la evolución y el desarrollo histórico de la comunicación de masas por las leyes de la acumulación capitalista" (Martín-Barbero, y Silva, 1997 p.14).

El segundo reduccionismo (la organización entendida desde la sola lógica del mercado) corresponde al reto que se planteó en el desarrollo de esta investigación: analizar la cultura organizativa (y por ende, la comunicación) de grupos sociales por fuera de modelos tecnócratas y financistas, cuyo origen está ligado a los desarrollos de la sociedad capitalista del último siglo.

En particular, averiguar sobre la juventud no se agota en las formas como los jóvenes se ven condicionados por las lógicas adultas, sino, como plantea Feixa (2003), que se debe analizar la construcción juvenil de la cultura, es decir, las formas mediante las cuales los jóvenes participan, creando y recreando, los procesos sociales de todo orden. Existe un escenario complejo de las diná- micas de la cultura que se vivencia en cualquier organización juvenil. Aunque no nos detendremos en hacer un análisis de la condición juvenil de las organizaciones, se considera implícito el contexto de análisis de estas organizaciones a partir del elemento de la juventud, como categoría sociohistórica cultural y relacional de las sociedades contemporáneas y que innegablemente influye en nuestro objeto de estudio. Así como Feixas, otros autores como Jesús Martín-Barbero, Óscar Dávila León, Nidya Constanza Mendoza y Rossana Reguillo han hecho reflexiones que respaldaron esta indagación.

Por otra parte, existen dos escenarios de la teoría acerca de la organización: uno, el de conceptualización desde la teoría euroccidental, que ha predominado ; y dos, el de la corriente latinoamericana, que parte de las particularidades de este contexto. La teoría organizacional administrativista, marcada por la lógica empresarial, plantea algunos elementos y conceptos que abren el camino para superar el lugar común que ha sido tradicional en las aplicaciones investigativa sobre este objeto de estudio.

La indagación en la literatura tradicional, inspirada en la administración, muestra que la escuela clásica --taylorista-, la escuela de las relaciones humanas, la escuela estructural moderna, la escuela de la organización como sistema de información, y la escuela de la organización como relaciones de poder (Zalpa, 2002), así como la racionalista clásica, la behaviorista, o la gerencial (Bartoli, 1992) han marcado la pauta de

1 En sus inicios, la teoría sobre los Movimientos Sociales se basó en los 'padres fundadores' de la sociología como Marx, Weber y Durkheim a mediados del siglo XIX; y en los ensayos sobre sicología de masas de Tarde, Le Bon y Freud, a finales del XIX e inicios del XX. En épocas más recientes (durante la década de los 60 del siglo XX), la Escuela de Chicago, a través del enfoque del Comportamiento colectivo -collective behaviour approach-, en el que se combinan el Interaccionismo Simbólico de Blumer (desde lo microsociológico), y el funcional estructuralismo de Parsons (desde lo macrosociológico), orientó los estudios de teoría social que predominaron en los Estados Unidos. (Riechmann, 1995: 16-18) 
la corporativización de los estudios acerca de las agrupaciones humanas ${ }^{2}$.

Las organizaciones que operan dentro del sistema de economía de mercado tienen como objetivo fundamental "rentabilizar" la inversión inicial a través de la venta de productos o servicios. Con ese interés, unas y otras compiten para diferenciarse y adquirir ventajas competitivas que les permitan atraer al consumidor. Internamente poseen una estructura física, generalmente organizada por departamentos, con funciones establecidas desde el principio. Hay accionistas, directivos, gestores, personal administrativo, operarios, distribuidores, servicios generales, etc. "Dentro de cada uno de estos grupos igualmente pueden hallarse diferencias, entre sus especialidades departamentales, su capacitación técnica, o sus diferencias sociológicas tipo edad, sexo, nivel de formación, etc., que definirán las características de las varias culturas del trabajo que convergen en una organización" (Colobrans, 1996, p. 263).

Esa generalizada corporativización de los estudios organizacionales hace sostener a más de un autor que las organizaciones sociales "se parecen cada vez más entre sí" a la forma de estructuración que inauguró la industria en la Modernidad (Lucas Marín, y García Ruiz, 2002, p. 8), opinión que se percibe bastante reduccionista y demuestra que el análisis antropológico o sociológico no tiene mayor presencia en las definiciones y análisis tradicionales sobre las organizaciones.

Aunque los sucesivos escritores de la escuela clásica plantearon nuevas reflexiones desde una óptica al parecer 'más humana', estas reflexiones no hicieron más que perfeccionar y disfrazar los postulados 'industrialistas' del taylorismo. En particular, Fernando Cruz Kronfly asegura que

2 En los análisis de la comunicación en las organizaciones, suelen encontrarse pasajes que aseveran que la comunicación organizacional está compuesta por "la comunicación institucional o corporativa, la comunicación interna, y la comunicación mercadológica (mercadotecnia y publicidad". (Rebeil Corella, 2000) estas posteriores escuelas simplemente desarrollaron formas "más eficaces para convertir al hombre en una máquina, en una pieza más dentro de la organización de la producción, aunque cuidándose de utilizar una terminología capaz de evidenciar esa condición" (2002, p. 147). Asegura, además, que más que diferencias, la mayoría de las teorías y escuelas de administración tienen elementos comunes que lo único que hacen es caer en los mismos "vacíos, silencios y ausencias teóricas" que obstaculizan la generación de un conocimiento científico de las organizaciones reales (2002, p. 125).

En otras palabras, se atrapa la realidad en formatos de pronóstico, minusvalorando la complejidad del ser humano, un enfoque que coincide con la predominante perspectiva que algunos proponen para entender la cultura organizativa: "La función de la cultura de la organización no puede ser otra que la de guiar el comportamiento hacia los modos de acción que convienen a la organización y a sus objetivos" (Lucas Marín, 1997, p. 73 - 74). Es decir, sería algo así como la utilización de la más básica expresión humana para beneficio de los 'dueños' del grupo; o en otras palabras, la instrumentalización de la vida misma. "En la mayoría de los casos, la preocupación sobre la comunicación en los contextos organizacionales se ha centrado en el diseño de estrategias de medios conducentes a cumplir metas operativas y productivas" (Martelo, y Calero, 2003, p. 7).

La instrumentalización de la cultura y la comunicación es propia de teorías como la teoría de sistemas y el funcionalismo. En palabras de Armand y Michelet Mattelart, ambas comparten un mismo concepto fundamental: el de función, que denota la primacía del todo sobre las partes. Particularmente, la ambición del sistemismo consiste en atender a la globalidad, a las interacciones entre los elementos más que a las causalidades, en comprender la complejidad de los sistemas como conjuntos dinámicos con relaciones múltiples y cambiantes" (Mattelart, y Mattelart, 1997, p. 44). 
Por ello, la teoría clave de esta investigación está apoyada en la teoría de la acción colectiva de Alberto Melucci, y la crisis de la modernidad de Alain Touraine. Lo anterior sirve de base para el tipo de agrupaciones que se analizaron, teniendo claros aspectos como que eran agrupaciones de menor o mayor grado de estructuración, y son muestra de la transformación de los movimientos sociales, de donde surge su denominación Nuevos Movimientos Sociales -NMS-, más centrados en la subjetividad que en el ideal racionalista de la Modernidad $^{3}$. Vale agregar que por menor o mayor grado de estructuración entendemos los niveles de dependencia y/o autonomía frente a organizaciones adultas o producto de una iniciativa estatal. Así, la teoría sobre Nuevos Movimientos Sociales -NMS-, ha dicho que estos movimientos expresan un estilo de acción no convencional, basada en la acción directa. Se establecen aspectos como el descentramiento, el rechazo a las lógicas jerárquicas tradicionales, y el claro interés en beneficiar fundamentalmente el entorno cercano. En ese sentido, sus prácticas organizativas están respaldadas en la toma de decisiones de forma participativa, en una estructura descentralizada y su discrepancia frente a las formas organizativas típicas de las democracias industriales occidentales (p. e. grupos religiosos o partidos políticos).

La base teórica organizativa de los NMS ha insistido en la horizontalidad de las relaciones, en la circularidad de los procesos comunicativos internos, y en el desafío de las jerarquías propias de los sistemas tradicionales de organización.

3 A finales de la década de los 70, se empiezan a dar transformaciones en las formas de movilización social. En una mutua alimentación entre realidad y teoría, las reclamaciones de las gentes cambiaron y las reflexiones al respecto tuvieron que darle una mirada distinta a tales realidades. En los 80 se relee a Gramsci, y a teóricos neomarxistas como Manuel Castells, Jordi Borda y Jean Lojkine, pero fundamentalmente a Alain Touraine. En ese sentido, "llama la atención que en la conceptualización sobre (nuevos) movimientos sociales se acudiera a autores europeos, más inclinados a indagar por los aspectos culturales y simbólicos, y no tanto a los norteamericanos, quienes para ese momento estaban postulando la 'movilización de recursos' para explicar las razones por las que un individuo se sumaba o no a la acción social colectiva."(Archila, 2001: 30-31)
En ese sentido, vale cuestionarse acerca de las formas de organizarse, a la luz de las identidades de estas agrupaciones. No podemos decir que todas reúnen las mismas características con que hasta ahora se han determinado los NMS (Dalton; Kuechler y Bürklin, 1992: 37), pero el reto está en ir construyendo sus recurrencias y similitudes, cuando, por ejemplo, muchas de ellas solo están permanentemente impulsadas por muy pocas personas, o han adelantado actividades de proyección social sin el apoyo de instituciones públicas o privadas. Incluso en muchas ocasiones los miembros de estas organizaciones no reciben mayor retribución que el agradecimiento de las comunidades por quienes trabajan, y rara vez estas actividades generan ganancias personales inmediatas.

Al respecto, Jorge Riechmann asevera: "La investigación empírica muestra que los objetivos ideológicos y colectivos pesan más que los cálculos egoístas para motivar a los individuos a que participen en grupos ambientalistas, protestas antinucleares y otras formas de acción colectiva."(1995: 22) En tales casos, ¿cómo explicar la existencia de estas agrupaciones a la luz del enfoque de elección racional aplicable a las organizaciones tradicionales?

Por ello, en un intento por complejizar las realidades sociales, se plantean dos grandes dimensiones para la regulación de la conducta social: la acción orientada por intereses y la acción orientada por normas. Al respecto, Fernando Uricoechea (2002) ha dicho que las formas de organización generan modos particulares de conducta, maneras apropiadas de actuar en el seno de ciertos contextos sociales.

Basado en Víctor Turner (quien distingue dos modelos de relaciones sociales: la estructura y la communitas $^{4}$ ), Uricoechea (2002) asevera que toda

\footnotetext{
4 La estructura es la sociedad tomada como "un sistema estructurado, diferenciado y frecuentemente jerárquico de posiciones político-jurídico-económicas, con muchos tipos de evaluación,
} 
organización creada espontáneamente termina por estructurarse tradicional o racionalmente (a la luz de la teoría weberiana). Es decir, el destino de la communitas es transformarse en 'estructura' como resultado de las previsiones y exigencias objetivas que provienen de las necesidades materiales del grupo. La satisfacción de esas necesidades por fuerza implicará el aparecimiento de relaciones estructuradas, y con ellas, la perversión de la idea de communitas.

\section{Metodología}

Para el análisis de los grupos juveniles (como manifestación de NMS) se consideró que los grupos sociales tienden siempre a que sus prácticas estén vinculadas a sus fines, y reediten de alguna manera lo que ha sido, consciente o inconscientemente, su historia colectiva de luchas y éxitos. De igual manera, las historias de prácticas anteriores se convierten en modelos para prácticas futuras, a la vez que son una manera como los más antiguos integrantes transmiten a los más nuevos la idea de identidad y pertenencia al grupo. Por ello, su idea implícita de organización puede establecerse a partir de la memoria de cada colectivo.

La memoria es un elemento esencial de la identidad, individual o colectiva, social o cultural. Ella se convierte en fuente clave para la reconstrucción de los elementos que dan sentido y contenido a la experiencia humana pasada y compartida dentro del grupo social, en su diaria lucha por sobrevivir a través de una serie de acciones en las que enfrenta a opositores, pero que también ha contado con aliados y ayudantes. Con el tiempo, esas peripecias pueden devenir en una

separando a los hombres de acuerdo con las nociones de 'más' o de 'menos'."

La communitas es una relación no estructurada que se desarrolla en los intersticios de la estructura, en su periferia. Trasgrede o anula las normas que gobiernan las relaciones estructuradas e institucionales. La communitas "goza de una cualidad existencial, abarca la totalidad del hombre en su relación con otros hombres completos". Allí el individuo reencuentra sus raíces colectivas y comunitarias profundas que son negadas por la estructura. Citado por Uricoechea (2002: 85 - 86) historia grupal idealizada basada en la eliminación de elementos turbios, y la sublimación de ciertas personas o acciones que se convierten en hitos que concentran los ideales más elevados del grupo. Así, la memoria selecciona, escoge, discrimina y transmite lo que le interesa que circule entre propios y extraños. Gracias a ella se reproducen valores y sistemas de pensamiento que competen no solo al individuo sino también a la colectividad.

De lo anterior se desprende la consideración de los mitos como narraciones acerca del origen del sistema social, y en cuya narración los actores asumen roles que luego se reproducirán en el orden social en que viven. El mito posee un valor simbólico intrínseco que se refiere simultáneamente al pasado, al presente y al futuro.

La manera como la gente recuerda el pasado, describe su presente o considera el futuro, está enmarcado por el contexto social de sus experiencias y su ubicación en la sociedad. El pasado siempre resulta filtrado por el presente y es constantemente revaluado, reasumido y reinterpretado, y lo es mediante un proceso activo de la colectividad. A través de la pertenencia a determinado grupo social, los individuos son capaces de adquirir, ubicar y evocar sus memorias, en un proceso reconocido como 'memoria colectiva'; que además es un recurso para la formación de grupos y para su cohesión, gracias a que explica la historia común, las experiencias compartidas y la trayectoria de la colectividad (Aceves, 1998: 233-234).

Lo anterior valida una atemporalidad para los sucesos que en él se narran, para explicar y dar sentido a las costumbres existentes remitiendo al "principio de los tiempos". Asimismo, el mito va a demostrar la pertenencia y la pertinencia del grupo que asume la historia reconocida, permitiendo construir un "nosotros" y un "los otros". En otras palabras, todo sistema social se sostiene sobre un mito fundacional que en mayor o menor medida le da origen y lo explica, permitiendo posicionar a los actores y justificar las relaciones que existen entre ellos. 
Así, la memoria de cada grupo juvenil fue la fuente primaria para establecer los puntos de toque y alejamiento de una a otra organización. La verbalización de la realidad que hay en cada individuo sirvió para crear y hacer consciente características que quizá no se reconocían. En igual sentido, "hasta que un grupo define y explicita sus sentidos, tomando conciencia de sí mismo como grupo, comienza a generarse en éste virtudes nuevas, atributos que no existían. Hasta que alguien define estos sentidos, los pronuncia y les pone palabras u otras expresiones discursivas, se construyen las virtudes de la organización" (Pérez, 2000, p. 105). Ello representó, para esta investigación, una fructífera y provocadora tarea pues se han encontrado vacíos en el abordaje de las organizaciones humanas desde una óptica esencialmente cultural, no condicionada por factores de lucro. Aunque cada persona se inserta en diferentes niveles grupales, ella en sí misma contiene una parte de la memoria de cada uno de esos grupos. Entonces, la entrevista, individual y grupal, fue la herramienta para la obtención de la información que sirvió para caracterizar las culturas organizacionales a partir de los valores, supuestos y creencias que surgieron durante sus relatos y apreciaciones de acontecimientos grupales.

Vale mencionar que la entrevista, en comparación con la observación etnográfica, permite indagar, a través del recuerdo, todas aquellas situaciones no observadas directamente. El difícil acceso a contextos naturales ya sea porque sucedieron en el pasado, o porque la presencia del investigador en escenarios comunes cohibiría la espontánea actuación de los integrantes del grupo estudiado, son razones de peso para adelantar este tipo de metodologías. En ese sentido, esta es una eficiente herramienta en el uso del tiempo de recolección de información, y se convierte, además, en "un excelente soporte para la descripción densa de la realidad fenomenológica" (Citado por Aceves, 1998, p. 309).
Para el registro de la memoria se tomaron elementos básicos de la teoría tradicional acerca de cultura organizativa. Específicamente, se realizaron entrevistas a los integrantes más antiguos de cada colectivo a partir de los diferentes estratos de la cultura organizacional propuestos por I. Chiavenato ${ }^{5}$ en combinación con la técnica de entrevista etnográfica de Spradley ${ }^{6}$.

Así, entonces, esos relatos de continuidades y rupturas organizativas permitieron a los miembros del grupo reconocerse por sus creencias, rituales e imaginarios comunes a través del tiempo. En ese sentido, decimos, con Maurice Halbwachs, que la memoria individual es colectiva ya que los recuerdos existen en la medida en que varias personas se encuentran para comunicarlos mutuamente y construir su veracidad. Ello sucede, por ejemplo, en los matrimonios, los entierros y las fiestas de un pueblo, que manifiestan las permanencias y la identidad colectiva.

Las organizaciones sociales pueden ser consideradas, entonces, como sistemas socioculturales. Sus componentes ideacionales (significados y valores, conocimientos y creencias) se integran al componente estructural, formando así un 'todo integrado', desde una concepción holística de la organización. Desde esa óptica, los mitos pueden ser definidos como interpretaciones de la realidad que sostienen los actos organizacionales y que son construcciones del espíritu almacenadas en las mentes de los integrantes.

5 Estrato 1 COMPONENTES (Tecnología, terreno o instalaciones, productos y servicios), Estrato 2 PATRONES DE COMPORTAMIENTO (Tareas, procesos de trabajo, normas y reglamentos), Estrato 3 VALORES Y CREENCIAS (lo que dicen o hacen todos los días; filosofía, estrategias y objetivos), y Estrato 4 SUPUESTOS BÁSICOS (creencias inconscientes, percepciones y sentimientos, concepción de la naturaleza humana, supuestos predominantes). CHIAVENATO, Idalberto. Comportamiento organizacional: la dinámica del éxito en las organizaciones. México: Thompson editores, 2004, p. 165

6 En esta técnica se plantean preguntas descriptivas, de contraste, hipotéticas, de reformulación, de búsqueda de lenguaje émico, estructurales, de repetición, de ejemplos, de experiencias y amistosas. Citado por MUÑOZ, José Federmán; QUINTERO, Josefina; y MUNEVAR, Raúl Ancizar. (2001, p. 141) 
Así, estas organizaciones juveniles se abordaron desde las redes de significación que se establecen cuando se comunican para adelantar sus actividades y que consecuentemente da vida a la organización. Ello se manifiesta en la memoria colectiva como forma sintética de las relaciones, funciones, actividades y recursos, y que dan forma a este tipo de organizaciones. En estos elementos se combinan tanto sus intereses sicoemocionales de la edad, como la ejecución de su 'acción social'. En resumen, la memoria de cada individuo -inserta en el respectivo grupo-, se convirtió en el insumo para establecer descriptivamente las coincidencias y diferencias organizativas, y por ende las características particulares y globales de estas organizaciones juveniles.

\section{Resultados}

Inicialmente podemos señalar cuatro aspectos coincidentes entre las organizaciones estudiadas:

1. En mayor o menor medida, estas organizaciones están ligadas al interés de uno o varios estudiantes universitarios (o a punto de serlo) por sacar adelante propuestas organizativas. A pesar de que muchos solo son bachilleres, siempre alguno de ellos utiliza los conocimientos obtenidos en la academia para orientar las actividades. Alejados de la dinámica de grupos religiosos o partidistas, el dominio (parcial o total) de un área profesional de varios de ellos posibilitó la creación de organizaciones en torno a un interés particular.

2. El año de creación o inicio no concurre con el año de obtención de la personería jurídica (si es que el respectivo grupo la tiene). Es decir, los 8 grupos juveniles escogidos (4 en cada ciudad) han desarrollado trabajo en sus comunidades desde hace varios años, sin que necesariamente, desde el principio, tuvieran que cumplir con el permiso legal para actuar. Sus miembros, unidos más por amistad que por dinero, no se han visto limitados por formalismos (como la personería jurídica o estatutos escritos de corporación) para desarrollar sus actividades. En otras palabras, la formalización de estas agrupaciones no ha sido impedimento para su existencia.

3. Varias de ellas reconocen que la presión de la sostenibilidad los llevó a adquirir carácter formal o legal porque debían sustentarse económicamente a través de la gestión de proyectos. Después de ello, se acogían a la exigencia de ofertar servicios y competir en convocatorias ante instancias tradicionales para la realización de proyectos de todo tipo.

4. Aunque en diferentes grados, cada una de estas agrupaciones ve en la producción audiovisual (o comunicativa, en general) un espacio de acción y expresión de intereses colectivos. Este punto se menciona, mas no se aborda pues el centro de estudio que nos corresponde se orienta a la cultura organizativa de estas agrupaciones.

\section{Historia y fases organizativas}

Basados, parcialmente, en los dos momentos de los colectivos humanos expuestos por Víctor Turner (citado por Fernando Uricoechea, 2002), podemos establecer una serie de etapas de creación y formación de este tipo de agrupaciones juveniles. En este punto vale decir que la experimentación siempre ha estado presente durante la existencia de estas agrupaciones juveniles. Cada etapa no tiene una duración determinada ni se aísla totalmente; el paso de una a otra puede ser imperceptible, y en ocasiones pueden mezclarse indistintamente. Las etapas serían las siguientes:

1. Etapa de surgimiento. Fase de fundación del grupo a partir de la inquietud de unos cuantos jóvenes que quieren adelantar acciones que satisfacen búsquedas personales sin dejar de lado la proyección social a una población determinada. Es la pregunta personal por el "¿qué quiero forjar 
en lo colectivo?", "¿qué puedo hacer por X personas?", "¿con qué cuento y qué me hace falta?". El no sometimiento a normativas o formalismos que los condicionen hace de esta etapa la más experimental de todas, lo que facilita poner a prueba las capacidades individuales y colectivas de acción, así como los mandos y jerarquías espontáneas. Esta etapa estaría enlazada al communitas de Turner.

2. Etapa de transición. Es el paso de la pequeña iniciativa a una fase de mayor seriedad del proyecto organizacional como una fuerza colectiva que intenta adelantar labores coordinadamente. Es el momento donde aparecen las preguntas: "¿cómo nos vamos a organizar?", "¿cómo nos vamos a financiar?", "¿qué vamos a ofrecer a la gente, a otras organizaciones y al Estado mismo?", "¿en qué debemos capacitarnos?". Aquí se reconoce la necesidad de someterse a unas reglas de juego establecidas por el mundo adulto desde antes de la aparición de la organización. En otras palabras, es la transformación de lo informal a lo formal. Una transformación que los hace compararse con otras organizaciones (de todo tipo) e iniciar alianzas con pares. En esta etapa el communitas se debilita para darle paso a la estructura.

3. Etapa de consolidación. Existe una fuerte convicción en los objetivos de la organización y una clara coordinación de tareas para la realización de actividades. Aunque todavía pueden existir aspectos por ajustar, cada miembro tiene claro su lugar y su papel en el grupo. Las preguntas de incertidumbre se atenúan para darle paso a las inquietudes por el mejoramiento de la agrupación interna y externamente. Se advierte un reconocimiento social y organizacional por la labor realizada hasta entonces. Eso les da aplomo para cobrar "lo justo" por sus servicios, acordar equilibradas alianzas, y adoptar posiciones ecuánimes frente a agentes estatales u organizacionales en general. Es la acentuación de la estructura de Turner.

4. Etapa de renovación. La quietud en las actividades de la organización puede significar un desgaste de los miembros y de las acciones del grupo. Es decir, los meses en los que el proceso llegue a estar "muy dormido" pueden repercutir en la transformación de iniciales objetivos del grupo, en la llegada de nuevos 'directivos' o en la separación de miembros que posteriormente podrían crear nuevos grupos o integrarse a otros. En este tipo de organizaciones, es típico que una organización dé vida a otras, y que unos miembros pasen de una a otra organización. También podemos decir que en esta etapa, la estabilidad de la estructura se ve cuestionada por fuerzas de distinto tipo que actúan sobre ella. Ello obliga a la estructura a reajustarse, innovarse o desaparecer.

\section{Situaciones comunes}

El anterior apartado sirve de base para describir las situaciones comunes que se establecieron en los relatos de los entrevistados. En general, las situaciones frecuentes fueron:
a. La toma de decisiones
b. La organización de actividades
c. La gestión de dinero
d. La relación con el Estado y con otras organi- zaciones

\section{Las decisiones}

Sus prácticas organizativas están respaldadas en la toma de decisiones de forma participativa, en una estructura descentralizada y su discrepancia frente a las formas organizativas típicas de las democracias industriales occidentales (p. e. grupos religiosos o partidos políticos).

Asimismo, estas agrupaciones, debido a su origen natural y voluntario, presentan estructuras simples, creadas espontáneamente, sin las formalidades que caracterizan a aquellas que desde un principio sabían que para lograr unos objetivos y adelantar unas actividades debían tener muy claro de qué manera se organizarían. 
A pesar de reconocer la adopción de estatutos y cuestiones de orden legal, ellos manifiestan rechazar los modelos de las organizaciones tradicionales y por lo que asumen internamente "otros modelos" de organización. Formalismos, como por ejemplo, la realización de actas de reuniones, en la práctica no siempre se aplican. Pero también se practican otros modelos de organización, como lo son las instancias de decisión que aunque no totalmente horizontales, sí ofrecen la oportunidad de mayor bidireccionalidad en los procesos de comunicación interna: la asamblea, es el principal. Pero aquí se presenta una de las debilidades de estas organizaciones: muchos de los integrantes realizan otras actividades paralelas (estudio o trabajo). Ello hace que cada vez que convocan a asamblea, difícilmente asistan todos.

La personería jurídica (como exigencia normativa de actuación interorganizacional) es un formalismo con una dinámica distinta a la dinámica y la relectura que cotidianamente realizan estos grupos en sus procesos internos. Pudiera decirse que uno es el ritmo externo (de las otras organizaciones), y otro el de estas en su vivir interno. De allí que no sea aplicable la teoría sistémica. Internamente hay otros ritmos de trabajo que no necesariamente son similares a los ritmos del trabajo de las organizaciones tradicionales, pero muestran exigencias básicas para el cumplimiento de sus productos o servicios. Además, la existencia de formalismo no significa efectividad en los correctivos que deban aplicar, intentando procesos de ajuste 'adentro-afuera'. Es decir, refuerzan la dinámica interna y revisan el accionar externo en todos los niveles. A veces lo logran rápidamente, a veces no.

A pesar de que todas las agrupaciones estudiadas son pequeñas (no superan las 15 personas), ellas se concentran en dos o tres de sus miembros, por lo general quienes iniciaron la agrupación. En este punto debe hablarse de la aparición de jerarquías internas. Aunque los miembros de estas organizaciones manifiesten rechazo a evidentes jerarquías, se percibe la existencia de autoridades atenuadas. En otros términos, el ideal participativo de largo aliento puede ser débil y posibilita prácticas autoritarias cotidianas: las 'autoridades' de cada grupo hacen respetar las reglas, que aunque implícitas, son normas básicas de comportamiento en todo momento donde está en juego el colectivo: respeto por la palabra ajena, uso adecuado de los implementos y espacios de la agrupación, inclinación por los objetivos generales del grupo, y defensa de la imagen del mismo, son ejemplo de ello. Sin embargo, las jerarquías no son irrebatibles y se reacomodan permanentemente.

Existe una flexibilidad que hace que quienes posean el poder dialoguen 'horizontalmente' con los de menor jerarquía. Por ejemplo, las propuestas de actividades surgen en conversaciones internas, espontáneas, niveladas. En ellas, las jerarquías desaparecen para darle paso a la igualdad en la generación de propuestas. Se discuten y se acuerdan tareas. Las tareas se establecen y designan según las habilidades, conocimientos o nivel de complejidad. A su vez, cada integrante busca acomodarse a las tareas que le son más afines a sus capacidades, habilidades, experiencia e intereses. En este punto, debemos recordar que las circunstancias de surgimiento y desarrollo de varias de estas organizaciones aminoran las situaciones de radical verticalidad propias de organizaciones más tradicionales.

Así, antes que la misma ubicación en un organigrama producto de un eventual cargo formal, los líderes adquieren tal estatus, producto de la antigüedad en la organización (quizá como fundadores de ella) y/o el mayor acervo de conocimiento, teórico o técnico. De igual manera, la historia de la organización otorga poder, voz y voto, a quienes en anteriores ocasiones propusieron acciones exitosas. Si el pasado le da sentido al presente y ayuda a vislumbrar el futuro, este sirve de referente verbalizado para la toma de decisiones a diario. 
Precisamente, en cuanto a la toma de decisiones, según la importancia de la decisión dentro de la organización, convocan por niveles de jerarquía, o convocan a todos los integrantes. Es decir, estas se asumen según los grados de importancia del asunto, iniciando con los niveles superiores y descendiendo, por decirlo de alguna manera, en forma de espiral, que se va agrandando hasta llegar a niveles amplios de participación. La realización de alguna actividad, la búsqueda de recursos, el ingreso de nuevos integrantes, e incluso la expulsión de miembros, se verifican de esta manera. Aseguran que quien convoca a cada reunión coordina la reunión. Sin embargo, casi siempre quien convoca es la 'junta directiva' (o quienes funjan como tales), encabezada por los líderes.

Asimismo, la espontaneidad de las reuniones de todo tipo es propia de estos grupos. El factor edad puede ser factor determinante en ellos para la evasión de acciones protocolarias, al punto que las reuniones (cualquiera sea el motivo de ellas) se caractericen por gastar parte del tiempo en charlar de manera distensionada, para después entrar a trabajar seriamente en el asunto que convoca.

Es frecuente que el ingreso de nuevos integrantes se haga por recomendación de terceros o por amistad de alguno de los integrantes. De todas maneras, para ellos, quienes a futuro quieran convertirse en integrantes, deben aportar al proceso y coincidir, lo más posible, con los fines de la agrupación. En otras palabras, en un primer momento es importante la amistad previa para ingresar a estas organizaciones, pero el elemento fundamental para invitar a otros a hacer parte del proceso es tener alguna habilidad o conocimiento que hasta el momento no se tiene, o merezca fortalecerse internamente en la organización, sin que eso signifique abrirle las puertas a cualquiera. Lo anterior coincide con el deseo permanente de fortalecer internamente la respectiva agrupación, antes que hacer una convocatoria abierta para eventuales ingresos de nuevos miembros. Ello también puede ser la expresión de cierto celo, un espíritu de gueto que salvaguarde la cohesión del grupo frente a eventuales nuevos miembros.

Se destaca también el deseo del aprendizaje mutuo y la formación permanente. Cada uno a su manera, dice un líder, "no puede quedarse con lo mínimo"; siempre se debe estar en el camino formativo o de mejoramiento personal y laboral, tanto en los productos como en los servicios a ofrecer. De allí que varias de estas agrupaciones apoyen a sus integrantes con el pago de parte de los gastos de estudio formal o capacitación no formal.

\section{Las actividades}

Los objetivos de cada organización varían según el espacio y las circunstancias que rodearon la conformación de cada grupo. Podría decirse que los objetivos de cada organización sirven para entender sus mayores preocupaciones organizativas. Hay que decir también que a pesar de que estas organizaciones plantean tener varios objetivos, siempre hay uno o dos objetivos que predominan en detrimento de los demás.

En términos generales, la producción audiovisual, la expresión estética y el empleo son los objetivos coincidentes con los que surgieron estas agrupaciones: en aquellas donde el objetivo fundamental es la expresión mediática, su preocupación es la obtención de equipos técnicamente suficientes para la realización de buenos productos. En las organizaciones de fines estéticos, las falencias en habilidades y criterios audiovisuales y/o mediáticos. Y en las organizaciones con propósitos de empleabilidad, las preocupaciones se centran en la realización y mantenimiento de actividades que generen ingresos para los integrantes.

Sin embargo, hay que aclarar que quienes hacen parte de organizaciones con fuertes fines 
"micropolíticos", no lo hacen necesariamente para emplearse, sino para abordar o señalar una realidad que los inquieta. En estos casos, el deseo de expresión personal y de grupo, en muchas ocasiones choca con la realidad material que una persona promedio se ve obligada a solucionar para sobrevivir. De allí que quienes se suman a estas agrupaciones no siempre conocen, o les interesen, los procesos de gestión ante entidades públicas o privadas. Aunque reconocen la importancia de la gestión, les parece una labor excesivamente esquemática, y esperan que alguien del grupo, que esté realmente interesado, asuma directamente esa tarea.

Caso contrario de las agrupaciones cuyos objetivos desde sus inicios son de solución de un problema claramente de tipo económico. En estas, existe una fuerte presencia de integrantes que lideran la gestión, personas que poseen conocimientos de administración, de alternativas de gestión y sostenimiento. Ello hace que los problemas de estas agrupaciones sean de otro talante: fragilidad de los fines sociales del grupo, así como inestabilidad en la permanencia de muchos de sus integrantes.

Lo anterior demuestra que las actividades grupales son expresiones de los objetivos colectivos. La acción colectiva está inspirada por unos fines en los que confluyen un grupo de personas. En este aspecto es donde más se verifica la orientación y los objetivos de los grupos. Es decir, los fines grupales se materializan en las acciones públicas y de proyección social que estas agrupaciones adelantan. Proyecciones de cine, bazares, encuentros lúdicos y deportivos, homenajes a habitantes zonales, participación en grupos de discusión con representantes del Estado, entre otros, son ejemplos de estas actividades. Las frecuencias de estas acciones varían en cada grupo juvenil, desde aquellos que se dedican exclusivamente a la producción audiovisual, hasta aquellos que mezclan actividades recreativas, culturales, e incluso de mero sostenimiento.
De todas maneras, las agrupaciones consideran que realizar actividades acordes con sus objetivos es aprender, practicar, foguearse, crecer personal y laboralmente. En tal sentido, una de sus preocupaciones son los vacíos teóricos o prácticos en áreas como elaboración de proyectos, gestión y legalización de recursos, manejo de los últimos formatos en video, etc. La preocupación se profundiza al no contar con el apoyo de instituciones públicas o privadas que gratuitamente les capaciten en estas áreas.

\section{La gestión}

Antes de hablar de gestión de proyectos, creemos importante hablar del factor financiero pues la sostenibilidad económica es quizá la mayor preocupación para estas organizaciones. No citamos este factor como una forma de generar interpretaciones que condenen el interés material de estas agrupaciones. Por el contrario, en el sistema capitalista el factor moneda se hace vital para la consecución de objetivos personales y/o colectivos; existen unas necesidades reales mínimas que presionan a diario, y que son inherentes al Occidente contemporáneo.

Precisamente el paso de la informalidad a la formalidad ha sido difícil para todas las agrupaciones pues les genera incertidumbre y presión, particularmente por las obligaciones económicas que eso genera. Pero esa presión está entrecruzada con los fines colectivos que, al menos de manera formal, intentan defender. Uno de los retos de la teoría de los Movimientos Sociales de hoy es estudiar estos grupos alternativos integrando al análisis la existencia de un sistema capital que genera tensiones sobre ellos y sus fines. Así, valoramos la iniciativa de estas agrupaciones juveniles por organizarse colectivamente y promover propuestas barriales alternativas al Estado y la empresa, aspectos que superan el factor necesidad.

Pero hay que decir que los niveles de gestión de estas agrupaciones se mueven en el terreno 
movedizo de las necesidades del momento, varían por épocas en cada organización, y según los grados de convicción y defensa de los principios fundamentales de cada una de ellas. Encontramos, entonces, que existen matices en las agrupaciones estudiadas: se percibe en varios integrantes que la remuneración por sus servicios a la organización es vital para el sostenimiento de su vida familiar; en tales grupos, la entrada y salida de personal es recurrente. Pero en otras organizaciones el respaldo financiero puede condicionar el accionar colectivo, pero no la permanencia de los integrantes en ella.

Por ello, la gestión de recursos a través de proyectos, en ocasiones busca, ante todo, generar ingresos para los integrantes como una forma generalizada de garantizar la permanencia de los miembros. Pero también hay casos en los que se pretende sacar adelante ciertas actividades independientemente de si quedan réditos. En otros, la gestión de recursos para una actividad busca, desde el principio, respaldo de cualquier tipo, en efectivo o en especie, con tal de efectuar la acción. No obstante, los ritmos y las dinámicas externas presionan a estas agrupaciones, en general, para que flexibilicen sus objetivos hasta el punto de tener que cumplir con una oferta de servicios.

Así, las experiencias pasadas les dan guía a estos jóvenes frente a lo que ha sido el grupo, pero actualmente les inquieta reconocer e impulsar los espacios para la gestión de todo tipo de propuestas, a la vez que la tenencia de los requisitos para concursar en convocatorias abiertas por instituciones públicas o privadas. Eso hace parte de sus acciones y preocupaciones presentes. Podríamos decir que ese momento de gestión muestra el choque entre la lógica institucional -adulta- y la lógica informal juvenil.

\section{Ante el Estado y otras organizaciones}

Su relación con otros grupos o instituciones está condicionada en ocasiones por las necesida- des y en otro por los ideales etarios. En particular, reconocen la existencia de unas normas estatales a las que se someten cuando se organizan formalmente, pero no dejan de desconfiar de eventuales intenciones veladas por parte de quienes representan al Estado. En igual sentido, desconfían de los partidos políticos, en particular en época de elecciones. De todas maneras, en los casos donde algún integrante gusta del partidismo, esa persona asegura mantener al grupo al margen de este interés. En general, los temores surgen en mayor o menor medida del eventual sacrificio de sus fines grupales.

Hay ocasiones en las que el fin condiciona las actividades, tratando de mantener al máximo los principios organizativos. En tal sentido, estas organizaciones han hecho alianzas (y a futuro están abiertas a hacerlas) con otras organizaciones o entidades que les ayuden a lograr sus fines. Sin embargo, son capaces de desistir de hacer acuerdos que pongan en peligro o anulen completamente a la agrupación. Pero hay que decir también que estas alianzas pueden estar condicionadas por la situación del momento. Por ejemplo, en una de las organizaciones de Medellín que actualmente pasa por un estado de quietud laboral (a comparación de épocas anteriores), las ofertas del Presupuesto Participativo de la Alcaldía pueden serle mucho más tentadoras que para otra de las organizaciones donde los ingresos por concepto de proyectos y servicios hoy por hoy son mucho más constantes.

Finalmente, a pesar de su intención de mostrarse como grupos compactos -en los que existe una unidad de criterios y fines-, dentro de estas organizaciones se manifiestan diferencias sutiles o abiertas que surgen cuando discuten el avance en los proyectos que se formalizarán externamente, cuando definen el destino de dineros que obtuvieron por la realización de proyectos, y cuando deciden cómo superar un impasse con compañeros a quienes ya no se les percibe con los mismos principios que les permitieron ingresar. No obstan- 
te, resuelven sus problemas de manera conjunta, y en ocasiones se consideran a sí mismos como 'hermanos', que a pesar de sus roces hacen lo que esté a su alcance para conservar ese "segundo hogar". Obviamente, quienes llevan la dirección y convocan a consultas para resolver el conflicto son los líderes naturales. Por eso reconocen que les falta mucho para ser organizaciones sólidas, pero eso no los desanima a seguir trabajando por sus comunidades.

A manera de síntesis, en la tabla 1 se concretan aspectos importantes de la cultura organizativa de las agrupaciones estudiadas.

Tabla 1

Características de la cultura organizativa de las agrupaciones estudiadas

\begin{tabular}{|c|c|c|}
\hline Valor o creencia & Descripción & Experiencia narrada \\
\hline $\begin{array}{l}\text { Presencia de líderes } \\
\text { 'horizontales' }\end{array}$ & $\begin{array}{l}\text { Uno o dos integrantes encabezan el } \\
\text { grupo ya sea por su antigüedad o por } \\
\text { sus conocimientos. No obstante, las } \\
\text { decisiones trascendentales se toman } \\
\text { en grupo. }\end{array}$ & $\begin{array}{l}\text { El líder o los líderes convocan } \\
\text { Mantienen las normas básicas de la } \\
\text { organización } \\
\text { Designan responsabilidades }\end{array}$ \\
\hline $\begin{array}{l}\text { Existencia de reglas bá- } \\
\text { sicas e implícitas }\end{array}$ & $\begin{array}{l}\text { Hay unas normas elementales que } \\
\text { pretenden mantener el grupo unido. }\end{array}$ & $\begin{array}{l}\text { Respeto por la palabra del otro } \\
\text { Cuidado de los implementos de trabajo } \\
\text { Equidad en la asignación de tareas }\end{array}$ \\
\hline $\begin{array}{l}\text { Formas alternas de tra- } \\
\text { bajo }\end{array}$ & $\begin{array}{l}\text { La concepción tradicional de jefe no } \\
\text { existe; los ritmos son libres y espon- } \\
\text { táneos, sólo condicionados por los } \\
\text { tiempos externos. }\end{array}$ & $\begin{array}{l}\text { Se 'parlotea' primero, se trabaja des- } \\
\text { pués. Los horarios de trabajo pueden } \\
\text { ser en fines de semana, u en semana } \\
\text { hasta altas horas de la noche. }\end{array}$ \\
\hline $\begin{array}{l}\text { Búsqueda del posicio- } \\
\text { namiento o reconoci- } \\
\text { miento en el contexto } \\
\text { cercano }\end{array}$ & $\begin{array}{l}\text { Realizar actividades de formación } \\
\text { y recreación alternos a los grandes } \\
\text { circuitos de la ciudad }\end{array}$ & $\begin{array}{l}\text { Cine a la calle } \\
\text { Tomémonos el parque } \\
\text { Muestras audiovisuales } \\
\text { Café al aire libre }\end{array}$ \\
\hline $\begin{array}{l}\text { Sostenibilidad de la or- } \\
\text { ganización }\end{array}$ & $\begin{array}{l}\text { Reconocen que sin la organización, } \\
\text { ellos no obtienen muchos de los } \\
\text { beneficios obtenidos hasta ahora. A } \\
\text { pesar de contratar con el Estado o la } \\
\text { empresa privada, cada organización } \\
\text { desearía tener recursos propios para } \\
\text { actividades libremente desarrolladas } \\
\text { por ellos. }\end{array}$ & $\begin{array}{l}\text { Búsqueda permanente de convocatorias } \\
\text { y licitaciones } \\
\text { Deseo de capacitación en gestión, o } \\
\text { contar con acompañamiento permanen- } \\
\text { te de expertos en el tema. }\end{array}$ \\
\hline $\begin{array}{l}\text { Priorización del factor } \\
\text { empleo }\end{array}$ & $\begin{array}{l}\text { Las actividades se piensan para que } \\
\text { genere ingresos a los miembros del } \\
\text { grupo. }\end{array}$ & $\begin{array}{l}\text { Repartición equitativa de las actividades } \\
\text { que generan recursos. }\end{array}$ \\
\hline
\end{tabular}




\begin{tabular}{|l|l|l|}
\hline \multicolumn{1}{|c|}{ Valor o creencia } & \multicolumn{1}{|c|}{ Descripción } & \multicolumn{1}{c|}{ Experiencia narrada } \\
\hline $\begin{array}{l}\text { División de tareas según } \\
\text { habilidades e intereses }\end{array}$ & $\begin{array}{l}\text { En ocasiones todos quieren hacer } \\
\text { una misma tarea, pero en tales casos } \\
\text { los líderes designan tareas. En este } \\
\text { asunto, la gestión es otra de sus } \\
\text { preocupaciones }\end{array}$ & $\begin{array}{l}\text { Muchos desearía solo dedicarse a } \\
\text { grabar o editar, pero el o los líderes no } \\
\text { permiten. Quisieran recibir capacitación } \\
\text { y acompañamiento para gestión de } \\
\text { proyectos. }\end{array}$ \\
\hline $\begin{array}{l}\text { Deseo de autonomía e } \\
\text { independencia }\end{array}$ & $\begin{array}{l}\text { Aunque respetuosos de los partidos, } \\
\text { las organizaciones tradicionales y las } \\
\text { entidades oficiales, prefieren guardar } \\
\text { la mayor distancia posible de estas. }\end{array}$ & $\begin{array}{l}\text { En época de elecciones, políticos de } \\
\text { oficio pretenden 'utilizarlos' para reco- } \\
\text { ger votos. Sin embargo, estos jóvenes } \\
\text { prefieren mantener a la organización al } \\
\text { margen de toda actividad proselitista. }\end{array}$ \\
\hline
\end{tabular}

\section{Conclusiones}

La cultura organizativa de los colectivos analizados en Medellín y Barranquilla se estructura a partir de un mito fundacional que orienta el accionar comunitario de los integrantes; es decir, la historia del grupo concentrada en las motivaciones y acciones acumuladas desde sus inicios se fueron convirtiendo en la base para la toma de decisiones y adelantar actividades sociales.

Específicamente, se hallaron varias expresiones que fueron comunes a los testimonios de los entrevistados. En el trasfondo de cada una de las expresiones están los elementos tradicionales del análisis de la cultura organizativa tales como jerarquías, estructura organizativa, valores y creencias. En ocasiones están entrecruzados, y en ocasiones logran aislarse con claridad. En ese sentido, la cultura organizacional creada en estas agrupaciones surge del entrecruzamiento de factores socioculturales, de género y de tiempo, en una época en la que la subjetividad pone a tambalear el ideal racional de la Modernidad.

Estos colectivos aparecen de una iniciativa que en la mayoría de los casos despertó en uno o dos jóvenes inquietos, con ganas de expresar su visión de mundo o de llegar a un sector de la población cercana a su realidad. Este origen espontáneo los llevó a trabajar, primero de manera informal, y luego, cuando vieron que podían efectivamente adelantar muchas más actividades, se organizaron formalmente.

La primera motivación fue generalmente espontánea, informal, y deseaba llegar a un público cercano y concreto. Luego, con el paso del tiempo, se fue formando un acumulado de experiencias a partir de las actividades sociales, que les alienta a organizarse formalmente a través de la obtención de la personería jurídica. Ese paso de lo informal a lo formal hizo que sus dinámicas internas para la organización de actividades, basada en relaciones de amistad y familiaridad, se transformaran y asumieran paulatinamente un carácter mucho más serio, más adulto.

Así, el mito de fundación, sus motivaciones y sus transformaciones grupales muestran que estos colectivos han pasado por diferentes etapas que manifiestan procesos de surgimiento, transición, consolidación o renovación organizativa. Aunque han padecido las tensiones producto de las necesidades domésticas de cada miembro de grupo, los intentos de cooptación por parte de grupos tradicionales, y la falta de apoyo de instituciones privadas o públicas, cada una de ellas, a su manera, hizo esfuerzos por sostener los objetivos sociales o culturales que desde el principio los impulsaron a organizarse. 
Allí se verificó su reconocimiento de las normas estatales. El paso de lo informal a lo formal les obliga asumir responsabilidades que antes no existían, y les genera temores pues representa de alguna manera la entrada al mundo de la organización tradicional, atada a las lógicas adultas -empresariales-. De igual manera, hay que reconocer que en algunas ocasiones no hay correspondencia exacta entre los presupuestos generales de la organización, y los intereses personales de sus miembros. No obstante, son versátiles para adaptar las exigencias de esa y otras formalidades, a sus ideales y fines personales y colectivos.

Esa doble tensión 'adentro-afuera', hace que toda organización se debata entre lo que conscientemente dice o hace, y lo que realmente se ha establecido en su historia desde y hacia ella. Ese es un riesgo permanente en medio de la sociedad contemporánea, extremadamente jerárquica y absorbente. En ocasiones, las organizaciones sociales pueden convertirse en instituciones reproductoras del orden y de la cultura política instituidas, pero en otras, también pueden ser fuerzas instituyentes de prácticas y sentidos emancipadores de abordar el poder y la democracia (Torres Carrillo, 2004, p. 19).

Por ello este trabajo pretendió tomar del área administrativista y del área antropológica los aspectos que les dieran una mejor lectura a estos grupos: una interpretación complejizada de la organización; una suerte de combinación de la cultura organizativa (no corporativa) entendida como insumo básico que está en el trasfondo de las maneras efectivas de comunicar en estas agrupaciones; una propuesta que intentó trascender el análisis tradicional de la circulación interna de información; una perspectiva enriquecida teóricamente que ayude a comprender, sin estigmatizar, a los grupos sociales. No fue una lectura de las interacciones diarias, ni una interpretación de su relación con las redes organizativas colegas. Fue una interpretación de los relatos de memoria guar- dados en la mente de los principales miembros de estos grupos; comprender cómo la producción social de sentido se manifestaba en sus relatos, y estos a su vez cómo explicaban la organización. En otras palabras, cómo las opiniones y representaciones de las historias compartidas, así como su estructura de significados, plantean la organización, "aquello que los sujetos que las componen creen que es esta" (Pérez, citado por Rebeill, 2000).

\section{Referencias bibliográficas}

Aceves, J. (1998). La historia oral y de vida: del recurso técnico a la experiencia de investigación. EN: Galindo Cáceres, Jesús (Coordinador). Técnicas de investigación en sociedad, cultura y comunicación. México: Pearson.

Archila, M. y Pardo, M. (2001). Movimientos sociales, Estado y democracia en Colombia. Bogotá: Universidad Nacional de Colombia.

Chiavenato, I. (2004). Comportamiento organizacional: la dinámica del éxito en las organizaciones. México: Thompson editores.

Colobrans, J. (1996). Ensayos de antropología cultural. España: Ariel

Dalton, R. y Kuechler, M. (1992). Los nuevos movimientos sociales: un reto al orden político. España: Edicions Alfons el Mangnànim.

Feixa, C. (2003). Del reloj de arena al reloj digital: Sobre las temporalidades juveniles. EN: Jóvenes. Revista de Estudios sobre Juventud (México). Vol. 7 No. 19. Julio - diciembre. pp. 6-27.

Lucas Marín, A. (1997). La comunicación en la empresa y en las organizaciones. Barcelona: Bosch Casa Editorial.

Lucas Marín, A. y García Ruiz, P. (2002). Sociología de las organizaciones. España: Mc Graw Hill.

Martín-Barbero, J. y Silva, A. (1997). Proyectar la comunicación. Bogotá: Tercer Mundo. 
Martelo, M. y Calero, S. (2003). La comunicación, las organizaciones y algunos casos de estudio. Cali: Corporación Universitaria Autónoma de Occidente.

Mattelart, A. y Mattelart, M. (1997). Historia de la teoría de la comunicación. Barcelona: Paidós.

Muñoz, J. F., Quintero, J. y Munevar, R. A. (2001). Cómo desarrollar competencias investigativas en educación. Bogotá: Magisterio.

Pérez, J. G. La aplicación de modelos de comunicación en las organizaciones (2000). EN: Rebeil Corella, M. A. y Ruízsandoval Reséndiz, C. El poder de la comunicación en las organizaciones. México: Plaza y Valdés Editores y Universidad Iberoamericana.

Riechmann, J. y Fernandez Buey, F. (1995). Redes que dan libertad: Introducción a los nuevos movimientos sociales. Barcelona: Paidós.

Thayer, L. (1975). Comunicación y sistemas de comunicación en las organizaciones, en la gestión directiva y en las relaciones interpersonales. Barcelona: Ediciones Península.
Torres Carrillo, Alfonso (2004). Organización y participación social y comunitaria: Una aproximación conceptual. EN: Organización y participación social en Colombia. ARIAS, Luis Alberto, et al. Bogotá: Fundación Universitaria Monserrate.

Torres Carrillo, A. (2006). Organizaciones populares, construcción de identidad y acción política. EN: Revista Latinoamericana de Ciencias Sociales, Niñez y Juventud. Universidad de Manizales (Manizales). Vol. 4. No.2. Julio-diciembre. pp. 1- 22.

Torres Carrillo, A. (2007). Identidad y política de la acción colectiva: organizaciones populares y luchas urbanas en Bogotá 1980-2000. Universidad Pedagógica Nacional. Bogotá: Editorial Nomos S. A.

Uricoechea, Fernando (2002). División del trabajo y organización social: Una perspectiva sociológica. Bogotá: Editorial Norma. 